\title{
An aqueous, polymer-based redox-flow battery using non-corrosive, safe, and low-cost materials
}

Tobias Janoschka, Norbert Martin, Udo Martin, Christian Friebe, Sabine Morgenstern, Hannes Hiller, Martin D. Hager \& Ulrich S. Schubert*

\section{PAPER ABSTRACT}

For renewable energy sources such as solar, wind, and hydroelectric to be effectively used in the grid of the future, flexible and scalable energy-storage solutions are necessary to mitigate output fluctuations. Redox-flow batteries (RFBs) were first built in the 1940s and are considered a promising large-scale energy-storage technology. A limited number of redox-active materials - mainly metal salts, corrosive halogens, and low-molar-mass organic compounds-have been investigated as active materials, and only a few membrane materials, such as Nafion, have been considered for RFBs. However, for systems that are intended for both domestic and large-scale use, safety and cost must be taken into account as well as energy density and capacity, particularly regarding long-term access to metal resources, which places limits on the lithiumion-based and vanadium-based RFB development. Here we describe an affordable, safe, and scalable battery system, which uses organic polymers as the chargestorage material in combination with inexpensive dialysis membranes, which separate the anode and the cathode by the retention of the non-metallic, active (macromolecular) species, and an aqueous sodium chloride solution as the electrolyte. This water- and polymerbased RFB has an energy density of 10 watt hours per litre, current densities of up to 100 milliamperes per square centimetre, and stable long-term cycling capability. The polymer-based RFB we present uses an environmentally benign sodium chloride solution and cheap, commercially available filter membranes instead of highly corrosive acid electrolytes and expensive membrane materials.

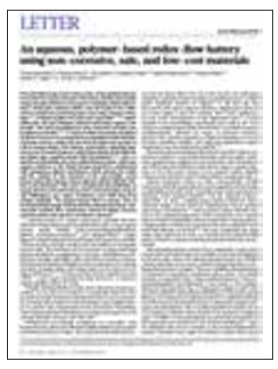

\section{SUMMARY}

Electricity users expect energy on demand. This poses a problem for renewables, such as solar, wind or hydroelectric, as the supply is naturally intermittent. Building scalable and inexpensive energy storage is the answer, and here we describe a new rechargeable battery system that uses salt solutions of organic polymers and a cheap filter membrane.

\section{The problem}

Despite our reliance on fossil fuels, more than a quarter of global powergenerating capacity comes from renewable power plants $(1,700$ gigawatts in 2014), with another 40 gigawatts in solar and 50 gigawatts in wind farms added each year ${ }^{1}$. Large-scale batteries are essential for dealing with the volatile electricity output from these sources and the resulting volatile energy prices. Redox-flow batteries, developed in the 1940s, are rechargeable batteries in which energy is stored in electrolyte solutions that are pumped through the cathode and anode compartments of flow cells separated by a porous membrane. Having external tanks of electrolyte makes it easy to increase the energy storage capacity by increasing the tank volume $e^{2-4}$. However, over the past 60 years, research into redox-flow batteries has focused largely on metal salts (such as vanadium) and costly membrane materials that can withstand the corrosive electrolytes ${ }^{5,6}$. A technology that is affordable and safe means moving away from materials that are strongly corrosive, scarce or toxic.

\section{The solution}

We replaced the metal salts and corrosive electrolytes in a redox-flow battery with simple organic polymers dissolved in aqueous sodium chloride solutions (see Graphical abstract). With these benign materials, we could replace expensive membrane materials (such as Nafion) with a simple filter membrane. Like a sieve, this membrane holds back large polymer molecules while allowing the smaller ions to pass. It thereby prevents intermixing of the anode and cathode solutions and prevents internal short-circuits of the battery. Such dialysis membranes are cheap and commercially available.

The organic polymers need to be highly water soluble and react at voltages where no water hydrolysis occurs. So we chose two redox-active components, TEMPO and viologen, owing to their good stability in water, and added co-monomers to further enhance their solubility. We prepared a battery test cell that used a simple filter membrane, two solutions of organic polymers in water, and table-salt. The cells demonstrated long-term stability (over 10,000 charging-discharging cycles) and 
reasonable current densities of $40 \mathrm{~mA} \mathrm{~cm}^{-2}$, up to a peak of $100 \mathrm{~mA} \mathrm{~cm}^{-2}$.

\section{The implications}

This battery is a first prototype so future research can improve further on its performance and storage capacity. A big challenge is energy density. Typical rechargeable lithium batteries achieve energy densities of 200-300 watt hours per litre; however, this battery technology does not allow an independent scaling of power and capacity. Our device currently achieves 10 watt hours per litre, which is $2-3$-fold less than the amount needed commercially (vanadium redox-flow batteries reach 20-40 watt hours per litre). This range should be achievable with polymer-based technology. A first step would be to optimize the polymer's solubility and the viscosity of the electrolyte solutions, perhaps by using (hyper)-branched polymers, rather than the linear polymers we used. Exploring other redox-active polymer components may also help to further boost cell voltage and therefore battery capacity. Our polymer-based redox-flow battery could pave the way to economical energy-storage devices for solar farms and wind turbines that rely on safe, metal-free and organic raw materials. The initial focus will be on batteries for wind farms. A single wind turbine has a power range of 2-6 megawatts, requiring 10-30 megawatt hours of battery capacity.

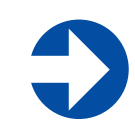

The full version of this article is at Nature's website at go.nature.com/28p5gkt

\section{GRAPHICAL ABSTRACT}

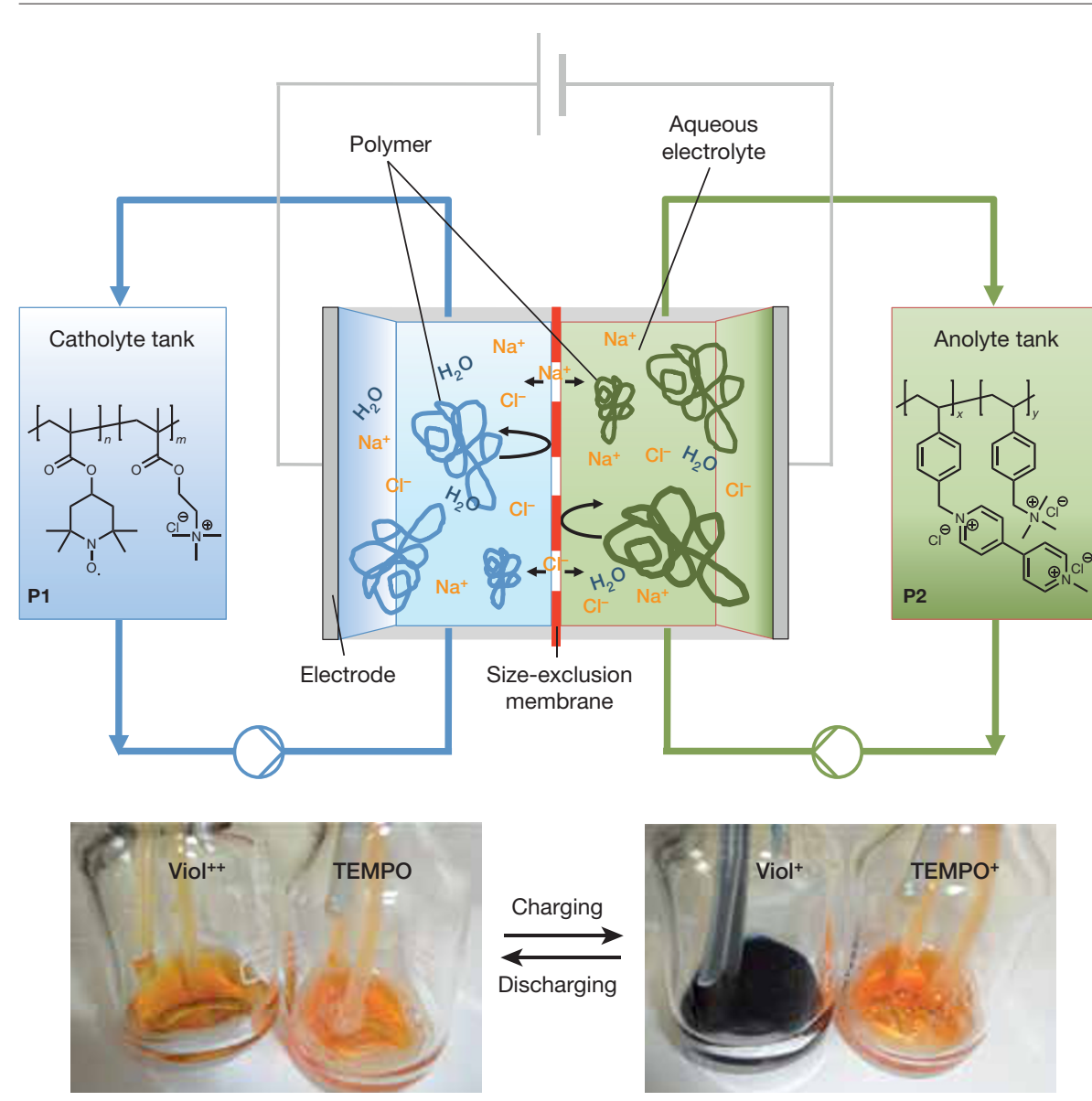

Rechargeable battery that uses safe, metal-free and organic raw materials. a, A polymer-based redox-flow battery consisting of an electrochemical cell and two electrolyte reservoirs filled with aqueous solutions of redox-active polymers. The anolyte and catholyte cycle are separated by a semipermeable dialysis membrane, which retains the redox-active macromolecules while allowing small salt ions to pass. During the charging-discharging process, a solution of the redox-active polymers P1 and P2 is continuously transported from the electrolyte reservoirs to the electrochemical cell, where the redox reactions take place. $\mathbf{b}$, Colour change of the polymer solutions upon charging-discharging.

\section{FURTHER READING}

1. REN21 Renewables 2015 Global Status Report (REN21 Secretariat, 2015).

This report summarizes the global development of renewable energy markets and policy frameworks.

2. Yang, Z. et al. Electrochemical energy storage for green grid. Chem. Rev. 111, 3577-3613 (2011).

Analysis of energy storage technologies and challenges facing the electricity grid.

3. Dunn, B., Kamath, H. \& Tarascon, J. M. Electrical energy storage for the grid: a battery of choices. Science 334, 928-935 (2011). Review of commercially available battery systems and a good introduction to energy storage for grid applications.

4. Alotto, P., Guarnieri, M. \& Moro, F. Redox flow batteries for the storage of renewable energy: a review. Renew. Sustain. Energy Rev. 29, 325-335 (2014)

A specialized review of the development of RFBs as well as state-of-the-art installations and future research questions.

5. Noack, J., Roznyatovskaya, N., Herr, T. \& Fischer $P$. The chemistry of redox-flow batteries. Angew. Chem. Int. Edn 54, 9776-9809 (2015). In-depth summary of the historical development of redox-flow batteries and overview of different redox-active materials.

6. Prifti, H., Parasuraman, A., Winardi, S., Lim, T. M. \& Skyllas-Kazacos, M. Membranes for redox flow battery applications. Membranes 2, 275-306 (2012).

Review of the membrane material that separates anode and cathode.

\section{RELATED CONTENT}

Synthesis and characterization of TEMPO- and viologen-polymers for water-based redox-flow batteries

T. Janoschka et al. go.nature.com/28zreve

Polymer/zinc hybrid-flow battery using block copolymer micelles featuring a TEMPO corona as catholyte

J. Winsberg et al.

go.nature.com/28zzibj

Poly(TEMPO)/zinc hybrid-flow battery: a novel, "green," high voltage, and safe energystorage system

J. Winsberg et al.

go.nature.com/28rhfdx 